\title{
Radical Hysterectomy
}

National Cancer Institute

\section{Source}

National Cancer Institute. Radical Hysterectomy. NCI Thesaurus. Code C94470.

The surgical removal of the uterus and surrounding structures, including bilateral pelvic lymph nodes, the parametrium, and the upper one-third to one-half of the vagina. 